Honey bee males and queens use glandular secretions to enhance sperm viability before and after storage

Den Boer, Susanne Petronella A; Boomsma, Jacobus Jan; Baer, Boris

Published in:

Journal of Insect Physiology

DOI:

10.1016/j.jinsphys.2009.01.012

Publication date:

2009

Document version

Publisher's PDF, also known as Version of record

Citation for published version (APA):

Den Boer, S. P. A., Boomsma, J. J., \& Baer, B. (2009). Honey bee males and queens use glandular secretions to enhance sperm viability before and after storage. Journal of Insect Physiology, 55(6), 538-543. https://doi.org/10.1016/j.jinsphys.2009.01.012 


\title{
Honey bee males and queens use glandular secretions to enhance sperm viability before and after storage
}

\author{
Susanne P.A. den Boer ${ }^{\mathrm{a}, *}$, Jacobus J. Boomsma ${ }^{\mathrm{a}}$, Boris Baer ${ }^{\mathrm{b}, \mathrm{c}}$ \\ ${ }^{a}$ Centre for Social Evolution, Department of Biology, University of Copenhagen, Universitetsparken 15, 2100 Copenhagen, Denmark \\ ${ }^{\mathrm{b}}$ ARC Centre of Excellence in Plant Energy Biology, MCS Building M310, The University of Western Australia, 6009 Crawley, Australia \\ ${ }^{\mathrm{C}}$ Centre for Evolutionary Biology, School of Animal Biology (MO92), The University of Western Australia, 6009 Crawley, Australia
}

\section{A R T I C L E I N F O}

\section{Article history:}

Received 11 November 2008

Received in revised form 13 January 2009

Accepted 23 January 2009

\section{Keywords:}

Apis mellifera

Ejaculate

Seminal fluid

Accessory glands

Spermatheca

Social insects

\begin{abstract}
A B S T R A C T
Internal fertilization requires live sperm to be transferred from male to female before egg fertilization. Both males and females assist the insemination process by providing sperm with glandular secretions, which have been inferred to contain subsets of proteins that maintain sperm viability. Here we show that in the honeybee (Apis mellifera) secretions of the male accessory glands, the major contributors towards seminal fluid, enhance sperm survival. We further demonstrate that the protein fraction of the male accessory gland secretion is indeed important for achieving the maximal effect on sperm survival. After sperm storage, the queens also provide sperm with secretions from spermathecal glands and we show that these secretions have a comparable positive effect on sperm viability. SDS gels show that the proteomic profiles of accessory gland secretion and spermathecal fluid secretion hardly overlap, which suggests that males and females use different proteins to enhance sperm viability during, respectively, ejaculation and final sperm storage.
\end{abstract}

(c) 2009 Elsevier Ltd. All rights reserved.

\section{Introduction}

Producing high quality ejaculates that remain viable during insemination is crucial for males to maximize their reproductive success (García-González and Simmons, 2005; Hunter and Birkhead, 2002), but how males actually influence the viability of their ejaculates remains unclear. In many species, males provide sperm with glandular secretions that are usually referred to as seminal fluid or seminal plasma, but details about the molecular composition of seminal fluid fractions are only available for a few insects such as fruit flies (Ravi Ram and Wolfner, 2007) and honeybees (Baer et al., in press; Collins et al., 2006) and several vertebrates including humans (Fung et al., 2004; Pilch and Mann, 2006). These seminal fluid components can affect both sperm cells and female physiology (reviewed by Chapman and Davies, 2004; Gillott, 2003; Poiani, 2006; Ravi Ram and Wolfner, 2007; Simmons, 2001) and at least some seminal fluid proteins have been predicted to enhance sperm viability and sperm survival (Baer et al., in press; Chapman and Davies, 2004).

Females are also known to provide sperm with glandular secretions. In vertebrates, bovine oviduct secretions have been shown to affect sperm motility and viability (Abe et al., 1995; Satoh

\footnotetext{
* Corresponding author. Tel.: +45 353213 41; fax: +45 35321250 .

E-mail address: spadenboer@bio.ku.dk (Susanne P.A. den Boer).
}

et al., 1995) and to enable sperm capacitation to increase fertilization success (King et al., 1994). Females of invertebrate species often possess specialized sperm storage organs (sometimes referred to as spermathecae) where sperm is kept between mating and egg fertilization (Eberhard, 1996; Simmons, 2001). These storage organs are often accompanied by glands and their secretions have been hypothesized to benefit the survival of stored sperm (Prokupek et al., 2008), although neither the molecular composition of these secretions nor their biological activity have been studied in great detail (but see Klenk et al., 2004; Koeniger, 1970; Lensky and Schindler, 1967).

Investigating the mechanisms by which males and females affect sperm viability is particularly interesting in the eusocial Hymenoptera (the ants and some of the bees and wasps). Copulations and insemination are restricted to a single brief mating episode early in a queen's life (Boomsma et al., 2005; Boomsma and Ratnieks, 1996). Males die during or shortly after copulating while queens store large amounts of sperm that remain viable over prolonged periods of time, sometimes for several decades (Keller, 1998; Pamilo, 1991). Reproductive success of males and queens is therefore likely to be correlated with both the quantity and the quality of the sperm cells that females are able to acquire and store (Cole, 1983). Male seminal fluid may thus be particularly important for sperm viability during the provisional storage of ejaculates in the female sexual tract prior to final storage. After transfer to the spermatheca, sperm might have to 
survive within the spermatheca for years before it will be able to fertilize eggs. It would thus seem obvious that glandular secretions from the queen's spermathecal glands are also important for sperm viability, but no explicit tests have been done to quantify such effects.

In a recent study on Atta leafcutter ants we showed that male accessory gland (AG) secretions, that were inferred to contribute most of the seminal fluid, have a positive effect on sperm viability even when sperm is only exposed to minute quantities of these secretions (Den Boer et al., 2008). In the present study we use the honeybee Apis mellifera to further examine this effect, by focusing on proteins within the AG secretion of males. We also test the effect of queen spermathecal secretion on sperm viability and examine whether the proteins produced in male and queen secretions are sex-specific. Honeybees have been a long standing model organism in biology, so that many basal aspects of its mating biology have been studied (for example see Koeniger, 1986; Koeniger et al., 1991; Koeniger and Koeniger, 1991). Apis mellifera queens mate with 12 males on average (Tarpy et al., 2004) and store up to 4.7 million sperm (Koeniger and Koeniger, 2000). The process of sperm storage can take up to $40 \mathrm{~h}$ (Woyke, 1983), where finally only $3-5 \%$ of the sperm is transferred to the spermatheca (Baer, 2005).

\section{Material and methods}

\subsection{Sampling of bees}

Bees used for the experiments originated from several colonies of Apis mellifera carnica that were kept at the University of Western Australia. Mature males and virgin queens became available during the Australian summer between October 2007 and January 2008 , a time span that includes the natural reproductive season of local honeybees. Mature males were collected from male producing colonies. Virgin females were obtained by grafting, whereby 4-day-old female larvae where reared into virgin queens using queenless colonies. Virgin queens were used for experiments at an age of 5-8 days after hatching, which is the typical period for nuptial flights (Ruttner, 1975).

\subsection{Dissections and sperm viability measurements}

Dissections were carried out with Inox 5 (Biology) watchmaker forceps in Hayes solution ( $9 \mathrm{~g} \mathrm{NaCl}, 0.2 \mathrm{~g} \mathrm{CaCl}_{2}, 0.2 \mathrm{~g} \mathrm{KCl}$ and $0.1 \mathrm{~g}$
$\mathrm{NaHCO}_{3}$ in $1000 \mathrm{ml} \mathrm{H}$ O, pH 8.7). Hayes solution was originally developed as a semen extender used for artificial insemination in honeybees and is a relatively simple saline solution that represents an environment that is similar to the inorganic fraction of the ejaculate (Schley, 1987). Because it has no added proteins, carbohydrates, fatty acids or amino acids, Hayes is expected to impose some physiological stress on the sperm cells. This makes Hayes saline ideal as a control solution to examine the positive effects of seminal fluid and spermathecal fluid proteins on sperm survival in an osmotically suitable but slightly suboptimal environment (see also Den Boer et al., 2008).

Sperm viability was measured using a Live/Dead ${ }^{\mathrm{TM}}$ sperm viability kit (L-7011, Molecular Probes; Collins and Donoghue, 1999; Den Boer et al., 2008). The kit consists of two fluorescent dyes that allow the experimenter to distinguish live (green emission, using SYBR-14 dye) from dead sperm cells (red emission, using propidium iodide). We used a Leica fluorescence microscope (blue excitation filter at $\lambda=490 \mathrm{~nm}$ ) at $400 \times$ magnification and counted the number of live (green), dead (red) and dual-stained sperm cells for at least 400 sperm cells for each sample. Dual stained sperm cells represented on average $0.13 \pm 0.03 \%$ (mean \pm S.E.M.) of the total sperm population and were therefore excluded from the data.

\subsection{The effect of AG secretion on sperm viability}

To investigate the effect of male AG secretion on sperm viability we collected 20 mature males. Each male was killed and his two accessory glands were dissected (Fig. 1A) and placed in $1 \mathrm{ml}$ Hayes saline. The glands were carefully ruptured to help the gland content dissolve into the Hayes saline. The sample was then vortexed and centrifuged for $3 \mathrm{~min}$ at $3000 \times \mathrm{g}$ to separate the soluble gland secretion from the remaining gland tissue. We also collected two sperm samples from the same male by puncturing each of his two accessory testes (also referred to as seminal vesicles, Snodgrass, 1956) in a drop of $4 \mu$ l Hayes and obtaining $2 \mu \mathrm{l}$ aliquots of the out flowing sperm in Hayes, using a micropipette. One of these was then dissolved in the $1 \mathrm{ml}$ Hayes solution containing AG secretion as described above, whereas the second sperm sample was dissolved in $1 \mathrm{ml}$ of Hayes only (control). Sperm viability was then estimated using $5 \mu$ l of each sample from which $>400$ sperm cells were counted (see above).

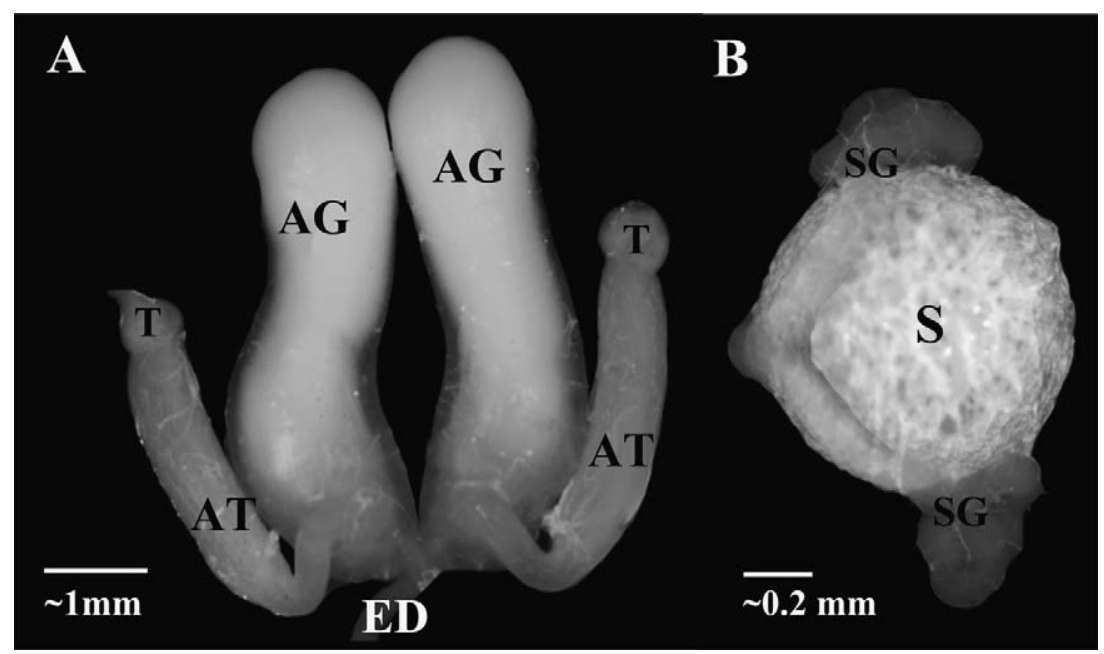

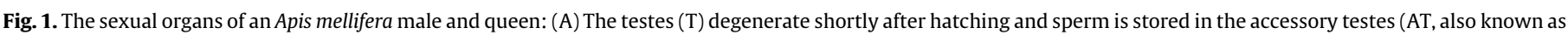

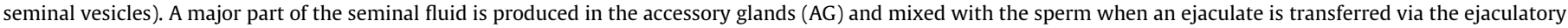

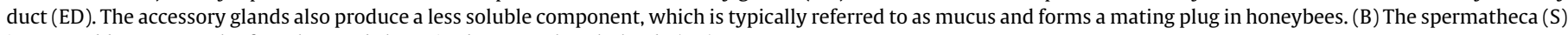
is covered by a network of trachea and the paired spermathecal glands (SG). 


\subsection{The effect of proteins in accessory gland secretion on sperm} viability

To test whether the protein fraction of the seminal fluid had a particularly distinct effect on sperm viability, we collected 25 mature males from several colonies. Their accessory glands were dissected and pooled in $500 \mu$ l Hayes saline. After rupturing the glands the solution was vortexed and centrifuged for $20 \mathrm{~min}$ at $20,000 \times g$ and $4{ }^{\circ} \mathrm{C}$ to separate the soluble secretion from the nonsoluble gland tissue and mucus. We then centrifuged the supernatant for $30 \mathrm{~min}$ at $10,000 \times \mathrm{g}$ and $20 \mathrm{~min}$ at $12,000 \times \mathrm{g}$ and $4{ }^{\circ} \mathrm{C}$ with a Millipore Ultrafree centrifugal filter device with a $5 \mathrm{kDa}$ cut off membrane. Because the smallest seminal fluid protein identified so far is $11 \mathrm{kDa}$ (Baer et al., in press), the vast majority of proteins, including all the ones hypothesized to be involved in sperm viability, did not pass through the membrane. Consequently we ended up with two subsamples that we refer to as the protein fraction (proteins above $5 \mathrm{kDa}$ ) and the non-protein fraction (peptides and other metabolites below $5 \mathrm{kDa}$ ) of the AG secretion. From a total of $180 \mu \mathrm{l}$ of protein fraction obtained, we used $30 \mu \mathrm{l}$ (equivalent to 4 males) for SDS-PAGE gel runs (see below) to visualize the protein profile, whereas the remaining $150 \mu \mathrm{l}$ (equivalent to 21 males) was diluted in $2 \mathrm{ml}$ of Hayes saline and used for sperm viability assays (see below). Of the $300 \mu \mathrm{l}$ of nonprotein fraction obtained, we used $48 \mu \mathrm{l}$ (equivalent to 4 males) for gel runs and the remaining $252 \mu$ l (equivalent to 21 males) for sperm viability assays after dilution in $2 \mathrm{ml}$ Hayes.

To test for the effects of AG proteins on sperm viability we used another 19 males. Three sperm samples of $1 \mu$ l each were collected from each male, by puncturing the accessory testes in a $3 \mu$ ldrop of Hayes saline and collecting the out flowing sperm with a micropipette. The sperm samples were diluted in $100 \mu$ l of (1) the protein fraction, (2) the non-protein fraction and (3) Hayes saline (control). Sperm viability was then estimated for a $5 \mu \mathrm{l}$ subsample of each treatment.

To visually compare the protein profile of AG secretion with that of seminal fluid of male ejaculates, seminal fluid was collected from an additional set of males according to a standardized protocol as outlined below and used for SDS-PAGE gel runs. Males were killed in chloroform, which stimulates ejaculation and thus allowed us to collect entire ejaculates. A total of $20 \mu$ l of pooled ejaculated sperm from 20 to 30 males was collected and diluted in $50 \mu \mathrm{l}$ Hayes solution, mixed and centrifuged for $25 \mathrm{~min}$ at $850 \times \mathrm{g}$ and $4{ }^{\circ} \mathrm{C}$ and afterwards for $10 \mathrm{~min}$ at $18,620 \times \mathrm{g}$ and $4{ }^{\circ} \mathrm{C}$ to separate sperm cells from the seminal fluid.

\subsection{The effect of spermathecal secretions on sperm viability}

To examine the effect of spermathecal fluid and spermathecal gland secretion on sperm viability, we used thirty virgin sister queens. The spermathecae and spermathecal glands of these queens were collected in $200 \mu$ l Hayes saline each (Fig. 1B). Both spermathecal glands and spermathecae were ruptured, vortexed and centrifuged for $3 \mathrm{~min}$ at $3000 \times \mathrm{g}$ to separate tissue from secretion. In addition, AG secretion was obtained from ten mature males as described in the previous sections. From each of these males we also collected four samples of $0.5 \mu \mathrm{l}$ sperm, by puncturing their accessory testes in $2 \mu \mathrm{l}$ of Hayes and collecting the out flowing sperm. The samples were dissolved in $100 \mu \mathrm{l}$ of (1) the spermathecal fluid secretion, (2) the spermathecal gland secretion, (3) male AG secretion and in (4) Hayes saline (control). Sperm viability was then estimated using $5 \mu \mathrm{l}$ aliquots.

SDS-PAGE was used to visualize the protein profiles of male AG secretions, seminal fluid, spermathecal glands and spermathecal fluid, using Biorad Criterion precast gels (10-20\% [w/v] Acrylamide, $\mathrm{HCl}, 1 \mathrm{~mm}, 18 \mathrm{comb}$ ). Gels were run at $30 \mathrm{~mA}$, fixed in a solution of $40 \%$ methanol and $10 \%$ acetic acid for an hour, and stained overnight with colloidal Coomassie blue (G 250). A total of $27 \mu \mathrm{g}$ of protein was loaded onto the gel for the seminal fluid, the AG secretion and the protein fraction of the AG secretion. For the non-protein fraction of the AG secretion, we loaded $15 \mu$ l of sample. For the spermathecal samples we loaded $20 \mu \mathrm{l}$ of spermathecal gland fluid and $8 \mu$ l of spermathecal fluid on the gel.

\subsection{Statistics}

Statistical analyses were carried out using SAS 9.1 for Windows. We examined the overall effect of treatment on sperm viability in all experiments using a generalized linear model with a binomial error distribution and a logit-link function, with treatment (the solution sperm was dissolved in) as repeated measure on the same male. The data were over-dispersed so we estimated the dispersion parameter from the scaled Pearson Chisquare. We used pair-wise contrasts to examine differences between treatment levels. To test for differences in overall sperm viability between males, we used the same generalized linear model, but with male as an independent class variable. $\chi^{2}$ values are presented for the treatment effects, linear contrasts and difference between males.

\section{Results}

Sperm viability was significantly higher in the presence of male AG secretions compared to the control treatment $\left(\chi^{2}=15.76\right.$, $\mathrm{df}=1, p<0.001$, Fig. $2 \mathrm{~A}$ ), but we found no significant difference between individual males in overall sperm viability $\left(\chi^{2}=26.09\right.$, $\mathrm{df}=19, p=0.128$ ).

When we tested for effects of the protein and the non-protein fraction of male AG secretion, we found significant overall differences $\left(\chi^{2}=15.19, \mathrm{df}=2, p<0.001\right.$, Fig. $\left.2 \mathrm{~B}\right)$. Sperm viability was significantly higher when exposed to the protein fraction of AG secretion compared to the non-protein fraction $\left(\chi^{2}=15.25\right.$, $\mathrm{df}=1, p<0.001$ ). Sperm viability was also significantly higher in the non-protein fraction compared to the control treatment $\left(\chi^{2}=5.92, \mathrm{df}=1, p=0.015\right)$, indicating that metabolites and peptides that were able to pass through the filter $(<5 \mathrm{kDa})$ enhance sperm viability as well, but that this effect is smaller. Similar to our first experiment we did not detect significant differences in sperm viabilities between individual males $\left(\chi^{2}=11.28, \mathrm{df}=18, p=0.882\right)$.

Visual inspection of 1D SDS-PAGE gels confirmed the absence of larger proteins in the non-protein fraction of the AG secretion (Fig. 3A, fourth lane) and showed that the profile of the protein fraction is similar to that of ejaculated seminal fluid, confirming that AG secretion is indeed the major contributor to seminal fluid in the honeybee.

When we tested the respective sperm viability enhancing effects of spermathecal fluid and spermathecal gland secretion, we found that they were similar, both to each other and to the effect of male AG secretion $\left(\chi^{2}=0.46, \mathrm{df}=2, p=0.796\right)$, whereas all three were significantly higher than the control $\left(\chi^{2}=7.77, \mathrm{df}=1\right.$, $p=0.005$, Fig. 2C). Once more, there was no difference in overall sperm viability between the males tested $\left(\chi^{2}=7.05, \mathrm{df}=9\right.$, $p=0.632$ ).

Inspection of the 1D SDS-PAGE gels (Fig. 3B) suggested that the protein profiles of spermathecal fluid and spermathecal gland secretion are visually comparable to those reported elsewhere (Klenk et al., 2004; Baer et al., submitted for publication). However, while the profiles for the spermathecal gland secretion and the spermathecal fluid were similar, both appear to be different from the profile of the male seminal fluid. This corresponds to the findings of Baer et al. (in press, submitted for publication), who 


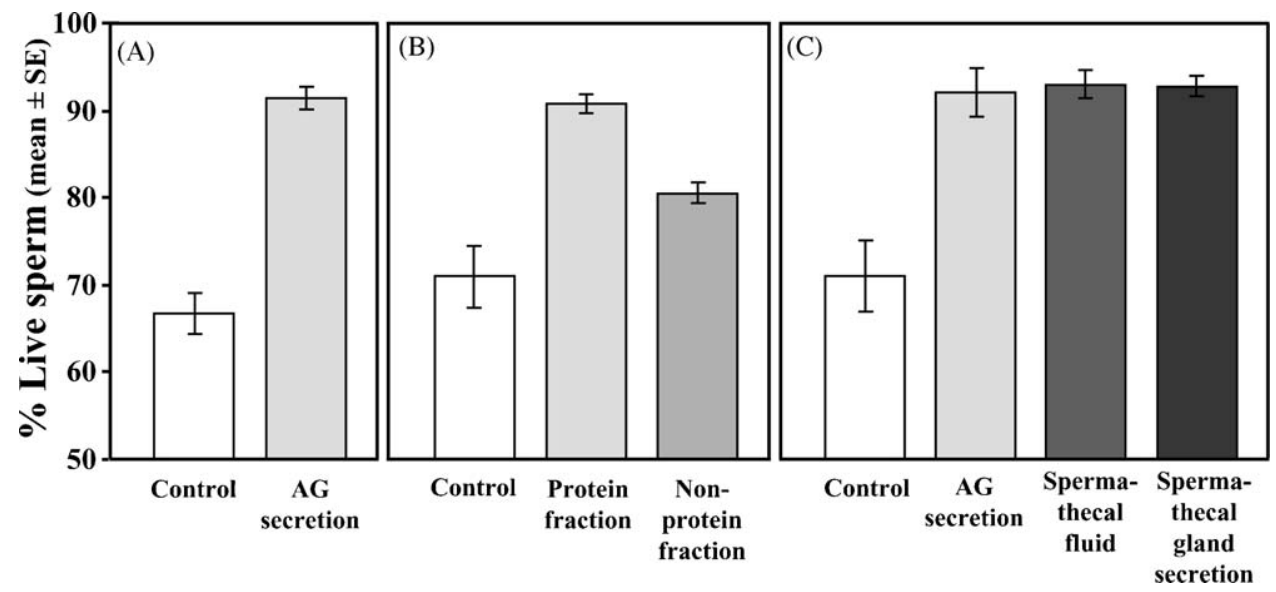

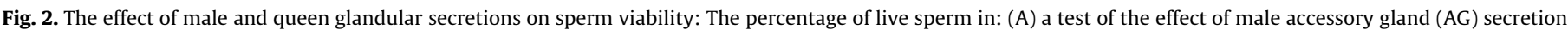

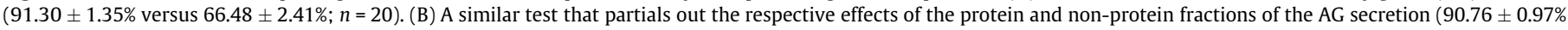

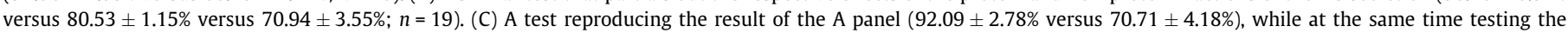
respective effects of spermathecal fluid and spermathecal gland secretion (92.95 $\pm 1.65 \%$ versus $91.82 \pm 1.48 \%$; $n=10$ in all four tests).

shows that the proteomic profiles of seminal fluid and spermathecal fluid hardly overlap.

\section{Discussion}

The transfer and storage of highly viable ejaculates is particularly important in social insects where queens never remate to replenish their sperm supply and sperm therefore needs to be

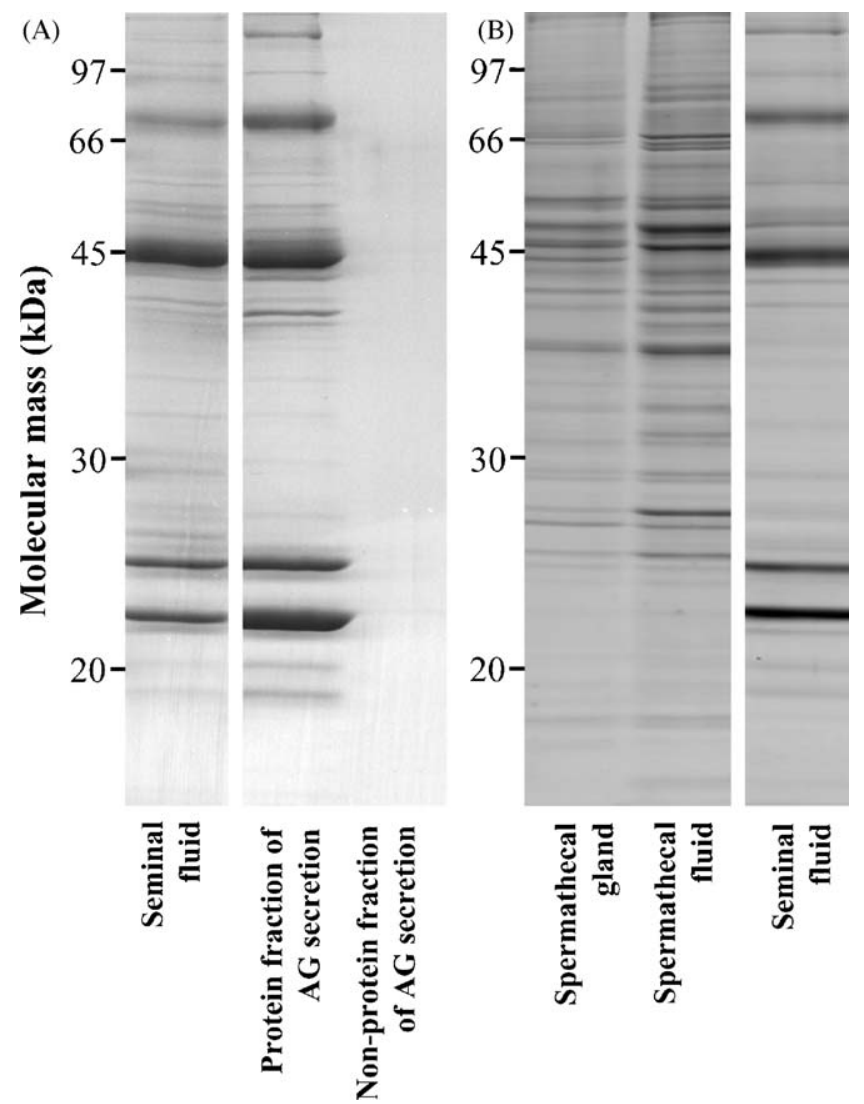

Fig. 3. Representative colloidal coomassie blue stained gels with lanes showing the protein profiles of male and queen glandular secretions: (A) Typical protein profiles for seminal fluid and protein and non-protein fractions of the accessory gland (AG) secretion. (B) The same for spermathecal gland secretion and spermathecal fluid, while also giving a seminal fluid profile from the same gel to show that the result is repeatable across different gel runs. kept viable for years (Boomsma et al., 2005). Adaptations in queens and males that prevent sperm death are therefore expected. Our study indeed shows that honeybee males and females both contribute glandular secretions that enhance sperm viability. In the sections below, we evaluate the implications of our findings, both by comparing our findings with older literature on sperm transfer and sperm storage in the honeybee, and by identifying novel questions of potential evolutionary trade-offs that may have shaped ejaculate and sperm storage traits. Finally, we discuss the molecular mechanisms that need to be clarified for a full understanding of the potency of these reproductive gland secretions.

\subsection{Male accessory gland effects on sperm survival}

Our work confirms that the AG secretions of males are of significant importance for sperm viability in the honeybee. As in our previous study on Atta leafcutter ants (Den Boer et al., 2008), our present data indicate that AG secretions are highly potent and express their positive effects on sperm survival even when diluted in a saline solution. In addition, we provide further evidence that the AG secretions are a main component of seminal fluid and are indeed transferred to the female as part of the ejaculate.

Secondly, we provide the first empirical evidence in insects for the hypothesis that proteins within the AG secretion are particularly important in maintaining sperm viable and that the non-protein fraction has a lesser, but also significantly positive, effect. Amino acids or sugars are likely candidates for producing this positive effect of the non-protein fraction, as they have previously been shown to increase sperm motility and sperm survival in honeybee semen (Verma, 1981; Poole and Edwards, 1970). We hypothesize that the effect of these metabolites on sperm survival may be relatively short-term (e.g. the duration of our experiment), while the proteins might be more important for maintaining sperm viability for the $40 \mathrm{~h}$ that sperm spend within the bursa copulatrix of queens before they are transferred to the spermatheca. An experiment to quantify the duration of the effect of the protein and non-protein seminal fluid components on sperm viability would therefore be interesting for future work. Likewise, it would be interesting to quantify whether the positive effect of the protein fraction is relatively more important in Apis mellifera honeybees than in $A$. florae and $A$. andreniformis dwarf honeybees (Koeniger and Koeniger, 1991; Koeniger et al., 1989) which, similar to Atta leafcutter ants (Baer and Boomsma, 2006), have sperm stored in 
the spermatheca without prestorage in the female reproductive tract.

\subsection{Queen spermathecal gland effects on sperm survival}

Similar to male seminal fluid, the queen spermathecal fluid and spermathecal gland secretion have positive effects on sperm viability. We found no difference between the treatments with spermathecal fluid and spermathecal gland secretion (Fig. 2C), which matches the observation that their protein profiles are very similar (Fig. 3B). The epithelium of the spermatheca itself lacks glandular structures, (Dallai, 1975) which underlines that the spermathecal glands are the source of the proteins found in the spermathecal fluid (also see Klenk et al., 2004). In addition, smaller molecules within the spermathecal environment seem important to keep sperm alive whilst in storage. For example, the honeybee spermatheca is known to have significantly higher concentrations of $\mathrm{Na}^{+}$and $\mathrm{K}^{+}$ions compared to the surrounding haemolymph, which has been hypothesized to act as a reversible inhibitor of sperm motility (Verma, 1973). The spermathecal lumen has also been found to have a surprisingly alkalic pH of 8.6 (Gessner and Gessner, 1976), which may induce sperm dormancy (Lensky and Schindler, 1967). Furthermore, elevated levels of anti-oxidant enzymes found in the spermatheca are likely to protect sperm cells from oxidative stress (Weirich et al., 2002).

By visually comparing the gels (Fig. 3B), we can conclude that that the protein profiles of male seminal fluid and queen spermathecal fluid are likely to differ considerably, which would indicate that the sexes accomplish their support functions for sperm viability in fundamentally different ways. Proteomic work by Baer et al. (in press, submitted for publication), where individual seminal fluid and spermathecal fluid proteins have been identified, confirms that there is little overlap between proteins produced in the male and queen glandular secretions. We hypothesize that this difference is related to the different time windows of male and female reproduction, so that seminal fluid primarily affects short-term sperm viability and spermathecal fluid is more important for long-term viability after storage.

\subsection{Understanding the functional significance of sperm support compounds}

Male AG secretions and seminal fluid are complex biochemical mixtures and are therefore likely to generate costs when males have to produce considerable amounts of these substances during their short adult lives. The peculiarities of eusocial hymenopteran mating systems imply that males do not renew their sperm and AG secretions (Boomsma et al., 2005), so that these costs may be a relatively constant proportion of total reproductive investment. However, this may be different in promiscuous mating systems where males are as long lived as females. A recent study on crickets showed that males adjust the viability of their ejaculates to the risk and intensity of sperm competition (Simmons et al., 2007; Thomas and Simmons, 2007). Future work should try to estimate these costs and the possible trade offs with sperm production itself. Social Hymenoptera may provide interesting opportunities to do such tests as the eusocial bees and several ant lineages have sister clades with single and multiple mating of queens (Hughes et al., 2008). The honeybee is a particularly suitable model system to study the trade-off between sperm number and sperm support secretions directly, because mating is lethal for males, so that males invest their life-time reproductive success in a single ejaculate and there are no additional trade-offs with later matings.

Our data are the first to give unambiguous support to the hypothesis that seminal fluid proteins are crucial for sperm viability. Relative to our previous study on the affect of AG secretion on sperm viability in Atta leafcutter ants, our present study in honeybees offers several additional insights because we were able to analyze the effect of both the male and female gland secretions on sperm viability and because the honeybee is a much better studied model system. For example, several studies have addressed aspects of the proteomic composition of honeybee seminal fluid (Baer et al., in press; Collins et al., 2006) and identified proteins that were hypothesized to enhance sperm survival. Future molecular work should now identify the functions of separate proteins, for example by using RNA knock outs, and by determining how natural variation in the presence or abundance of these proteins translates into ejaculate quality and paternity success.

Similar to male seminal fluid the spermathecal gland secretions are also likely to be a highly complex mixture of proteins and metabolites. A recent study (Baer et al., 2006) showed that colonyfounding queens of Atta leafcutter ants may pay a substantial cost for storing higher than average amounts of sperm as this apparently trades off with their immune response during this vulnerable solitary stage in their life. Such trade offs are less likely to apply in honeybees, who found new colonies by swarming so that young queens are always well provisioned. However, both Apis honeybees and Atta leafcutter ants have queens that are considerably more long-lived than queens of sister groups such as Bombus bumblebees and Trachymyrmex fungus-growing ants. It would thus be highly interesting to obtain comparative data on the identity and production costs of spermathecal proteins that secure the viability of stored sperm for one or a few years, relative to those active in queens that live for decades.

\section{Acknowledgements}

We thank the honeybee keepers of Western Australia (Better bees of Western Australia) and especially Tiffane Bates, Ron Clark and Harry East (Boss Lady Queens), for providing the necessary bee material and Kar-Chun Tan for providing the SDS gels. This work was supported by grants from the Danish National Research Foundation to JJB and an Australian Research Council (ARC) Queen Elizabeth II Fellowship to BB.

\section{References}

Abe, H., Sendai, Y., Satoh, T., Hoshi, H., 1995. Bovine oviduct-specific glycoprotein-a potent factor for maintenance of viability and motility of bovine spermatozoa in-vitro. Molecular Reproduction and Development 42, 226-232.

Baer, B., 2005. Sexual selection in Apis bees. Apidologie 36, 187-200.

Baer, B., Armitage, S., Boomsma, J.J., 2006. Sperm storage induces an immunity cost in ants. Nature $44,872-875$.

Baer, B., Boomsma, J.J., 2006. Mating biology of the leaf-cutting ants Atta colombica and A. cephalotes. Journal of Morphology 267, 1165-1171.

Baer, B., Heazlewood, J.L., Taylor, N.L., Eubel, H., Millar, A.H., in press. The seminal fluid proteome of the honeybee Apis mellifera. Proteomics.

Baer, B., Eubel, H., Taylor, N.L., O'Toole, N., Millar, H.A. Insights into female sperm storage from the spermathecal fluid proteome of the honeybee Apis mellifera. Genome Biology, submitted for publication.

Boomsma, J., Baer, B., Heinze, J., 2005. The evolution of male traits in social insects. Annual Review of Entomology 50, 395-420.

Boomsma, J., Ratnieks, F., 1996. Paternity in eusocial Hymenoptera. Philosophical Transactions of the Royal Society of London Series B-Biological Sciences 351 947-975.

Chapman, T., Davies, S., 2004. Functions and analysis of the seminal fluid proteins of male Drosophila melanogaster fruit flies. Peptides 25, 1477-1490.

Cole, B., 1983. Multiple mating and the evolution of social behavior in the Hymenoptera. Behavioral Ecology and Sociobiology 12, 191-201.

Collins, A.M., Caperna, T.J., Williams, V., Garrett, W.M., Evans, J.D., 2006. Proteomic analyses of male contributions to honey bee sperm storage and mating. Insect Molecular Biology 15, 541-549.

Collins, A.M., Donoghue, A.M., 1999. Viability assessment of honey bee Apis mellifera sperm using dual fluorescent staining. Theriogenology 51, 1513-1523.

Dallai, R., 1975. Fine structure of the spermatheca of Apis mellifera. Journal of Insect Physiology 21, 89-109.

Den Boer, S.P.A., Boomsma, J.J., Baer, B., 2008. Seminal fluid enhances sperm viability in the leafcutter ant Atta colombica. Behavioral Ecology and Sociobiology 62, 1843-1849. 
Eberhard, W.G., 1996. Female Control: Sexual Selection by Cryptic Female Choice. Princeton University Press, Princeton.

Fung, K., Glode, L., Green, S., Duncan, M., 2004. A comprehensive characterization of the peptide and protein constituents of human seminal fluid. Prostate 61, 171-181.

García-González, F., Simmons, L.W., 2005. Sperm viability matters in insect sperm competition. Current Biology 15, 271-275.

Gessner, B., Gessner, K., 1976. Inorganic ions in spermathecal fluid and their transport across the spermathecal membrane of the queen bee, Apis mellifera. Journal of Insect Physiology 22, 1469-1474.

Gillott, C., 2003. Male accessory gland secretions: modulators of female reproductive physiology and behavior. Annual Review of Entomology 48, 163-184.

Hughes, W.O.H., Oldroyd, B.P., Beekman, M., Ratnieks, F.L.W., 2008. Ancestra monogamy shows kin selection is key to the evolution of eusociality. Science 320, 1213-1216.

Hunter, F., Birkhead, T., 2002. Sperm viability and sperm competition in insects. Current Biology 12, 121-123.

Keller, L., 1998. Queen lifespan and colony characteristics in ants and termites. Insectes Sociaux 45, 235-246.

King, R., Anderson, S., Killian, G., 1994. Effect of bovine oviductal estrus-associated protein on the ability of sperm to capacitate and fertilize oocytes. Journal of Andrology 15, 468-478.

Klenk, M., Koeniger, G., Koeniger, N., Fasold, H., 2004. Proteins in spermathecal gland secretion and spermathecal fluid and the properties of a $29 \mathrm{kDa}$ protein in queens of Apis mellifera. Apidologie 35, 371-381.

Koeniger, G., 1970. Bedeutung der Tracheenhülle und der Anhangsdrüse der Spermatheka für die Befruchtungsfähigkeit der Spermatozoen in der Bienenkönigin (Apis mellifera L.). Apidologie 1, 55-71.

Koeniger, G., 1986. In: Rinderer, T.E. (Ed.), Bee Genetics and Breeding. Academic Press Inc., London, pp. 255-280.

Koeniger, G., Koeniger, N., Mardan, M., Otis, G., Wongsiri, S., 1991. Comparative anatomy of male genital organs in the genus Apis. Apidologie 22, 539-552.

Koeniger, N., Koeniger, G., 1991. An evolutionary approach to mating behaviour and drone copulatory organs in Apis. Apidologie 22, 581-590.

Koeniger, N., Koeniger, G., 2000. Reproductive isolation among species of the genus Apis. Apidologie 31, 313-339.

Koeniger, N., Koeniger, G., Wongsiri, S., 1989. Mating and sperm transfer in Apis florea. Apidologie 20, 413-418.

Lensky, Y., Schindler, H., 1967. Motility and reversible inactivation of honeybee spermatozoa in vivo and in vitro. Ann Abeille 10, 5-16.

Pamilo, P., 1991. Life-span of queens in the ant Formica exsecta. Insectes Sociaux 38 , 111-119.
Pilch, B., Mann, M., 2006. Large-scale and high-confidence proteomic analysis of human seminal plasma. Genome Biology 7, R40.

Poiani, A., 2006. Complexity of a seminal fluid: a review. Behavioral Ecology and Sociobiology 60, 289-310.

Poole, H.K., Edwards, J.F., 1970. Induction of motility in honey bee (Apis mellifera L.) spermatozoa by sugars. Experientia 26, 859-860.

Prokupek, A., Hoffmann, F., Eyun, S.-I., Moriyama, E., Zhou, M., Hashman, L., 2008. An evolutionary expressed sequence tag analysis of Drosophila spermatheca genes. Evolution 62, 2936-2947.

Ravi Ram, K., Wolfner, M., 2007. Seminal influences: Drosophila Acps and the molecular interplay between males and females during reproduction. Integrative and Comparative Biology 47, 427-445.

Ruttner, F., 1975. Die instrumentelle Besamung der Bienenkönigin. Apimondia Publishing House, Bucharest.

Satoh, T., Abe, H., Sendai, Y., Iwata, H., Hoshi, H., 1995. Biochemical characterization of a bovine oviduct-specific sialo-glycoprotein that sustains sperm viability in vitro. Biochimica et Biophysica Acta-Mollecular Cell Research 1266, 117-123.

Schley, P., 1987. Einführung in die Technik der instrumentellen Besamung von Bienenköniginnen. Köhler Offset KG, Giessen.

Simmons, L., Denholm, A., Jackson, C., Levy, E., Madon, E., 2007. Male crickets adjust ejaculate quality with both risk and intensity of sperm competition. Biology Letters 3, 520-522.

Simmons, L.W., 2001. Sperm Competition and its Evolutionary Consequences in the Insects. Princeton University Press, Princeton.

Snodgrass, R.E., 1956. Anatomy of the Honeybee. Cornell University Press, London.

Tarpy, D., Nielsen, R., Nielsen, D., 2004. A scientific note on the revised estimates of effective paternity frequency in Apis. Insectes Sociaux 51, 203-204.

Thomas, M., Simmons, L., 2007. Male crickets adjust the viability of their sperm in response to female mating status. American Naturalist 170, 190-195.

Verma, L.R., 1973. An ionic basis for a possible mechanism of sperm survival in the spermatheca of the queen honey bee (Apis mellifera L.). Comparative Biochemistry and Physiology 44, 1325-1331.

Verma, L.R., 1981. Biology of the honey bee spermatozoa. 3. Effect of the amino acids and catalase on respiration as measured by the cartesian diver technique. Apidologie 12, 377-382.

Weirich, G., Collins, A., Williams, V., 2002. Antioxidant enzymes in the honey bee, Apis mellifera. Apidologie 33, 3-14.

Woyke, J., 1983. Dynamics of entry of spermatozoa into the spermatheca of instrumentally inseminated queen honeybees. Journal of Apicultural Research 22, 150-154. 